\title{
"Green Multi Business Models" How to measure Green Business Models and Green Business Model Innovation?
}

\section{Peter Lindgren ( $\nabla$ peterli@btech.au.dk)}

Aarhus University: Aarhus Universitet https://orcid.org/0000-0002-4949-8706

Niklas Stoyan Hornbæk Knoth

Aarhus University: Aarhus Universitet

\section{Sukanthan Sureshkumar}

Aarhus University: Aarhus Universitet

Mathilde Fogh Friedrich

Aarhus University: Aarhus Universitet

\section{Rita Adomaityte}

Aarhus University: Aarhus Universitet

\section{Research Article}

Keywords: Green Business Model measurement, Green Business Model innovation, Green Business Model development, Green Business Model parameters, Green Multi Business Model Innovation,.

Posted Date: June 9th, 2021

DOI: https://doi.org/10.21203/rs.3.rs-442665/v1

License: (c) (i) This work is licensed under a Creative Commons Attribution 4.0 International License. Read Full License 


\section{Abstract}

2000s and early 2010's, academia's, businesses and societies have been experimenting with how to measure green business models design - creating, capturing, delivering, receiving and consuming TO BE Business Models and business model reconfiguration - focusing on changing AS IS Business Models into becoming or being green and green business model development BM development tactical parameters, tools and actions.

In the last few years, businesses and even countries have been caught in green washing, some due lack of knowledge on what is green and others because of strategic chosen green washing strategy. It seems as if there is a gap in literature and practice on how to measure green business models and more specifically How to define and measure green related to business models. None seems to be able to measure green business models in real time because there is no clear definitions of green business model parameters and therefore it is very difficult to develop tools that can measure green business models. Numerous green certificates exist and several consultancies tries to rule the billion dollar green business model certificate ecosystem for measuring and validating transformation of Business model ecosystems, businesses and their business models into green. However, most definitions and certificates seem to be static and related iso measurement tools seems not to be able to measure green in realtime. Several practice, certificates and standards include former iso standards pitfalls, pains and potentials to "jump the fence". Finally, most green business model approach take the point of entry from the technical and/or the sustainable, circular and UN 17 goals view and not really from the efficiency and business model dimension and level view. Green Business Model Innovation, Development and Measurement calls therefore for new and more advanced green business model innovation measurement tools.

The paper presents some primarily work on green business model definition, tool innovation and development on measuring green on business models - The Green Business Model Dashboard. The paper reports on an innovation of a green business model dashboard enabling measurements of how green a business and its business models really are at anytime. As the name Green Business Model - point of entry is taken from a business model viewpoint and perspective. The research relates to a careful review of business model and green business model literature and practice. It builds on investigation of different green business model innovation projects and propose a new framework and dashboard on how to measure green business models in real time embedded with and supported by advanced wireless technologies. The goal is to achieve greater understanding of how green business model innovation and development take place and to take Green Business Model Innovation and research into the next step of business model and advanced wireless technologies innovating, offering future research directions.

\section{Introduction}

No doubt many business are motivated and pushed by society and stakeholders on innovating and developing Green business models (GBM). However, it is well known that reconfiguring existing business models (BM) is complex but it is not that known that reconfiguration of BM's to become efficient GBM's is even more complex and resource consuming. The reason is that it includes balancing monetary and non-monetary value formulas of the GBM's and further development of indispensable GBM's strategies to commit the business to the green economy. Further it includes Green Business Model Innovation (GBMI) on all business model dimensions and levels.

More and more businesses are although aiming at transforming into green. The term "Green Business Model" (GBM) as used in our framework, terminology and vocabulary relates to the environmental dimension of green (e.g. Use of Material and Resources, Consumption of Material and Resources, Waste, Pollution, Recycling of BM, Waste and Pollution) and the business economic perspective (e.g. turnover - cost = earnings, efficiency). The GBM construction perspective in our terminology focus on an input and output that becomes an operative GBM that are both environmentally (Green Business Model Parameters) and economically sustainable (Economic Business Model Parameters) to the business and its Business Model Ecosystem (BMES) through out the entire lifecycle of the GBM and its related BM's and BMES's.

Businesses today are globally involved to execute their business role to minimize environmental damage effects - but at the same time also responsible in a world of capitalism to try to capitalize on the green economy and their GBM's. Advanced ICT is in this case increasingly playing an essential part of this green transformation in businesses and their related BMES to act upon the 
climate change and balance their related BMES's through technologies and GBM's to fight environmental challenges as e.g. higher temperatures, Co2 emission, numerous frequencies of floods and storms, lack of food and water, pressure on health care system, biodiversity both in Atmosphere, soil and in water.

Green transformation includes less among other green parameters reduced use of energy and non -renewable materials and resources, increased delivery of reliable renewable energy supplies called green energy and Green Business Model Innovation (GBMI). It includes the investment in GBM through digitalization of the GBM's. Scientists and researchers from both businesses and academia discuss however heavily how to deploy and measure GBM strategies in an efficient way in the entire Green Business Model Process as indicated in Fig. 1.

Our long term approach related to measurement of GBM and GBMI is to measure on all phases as shown in Fig. 1 but not just on the individual BM, Business and BMES but on the entire value network. However at this point we begin the measurement from the inside of the BM, Business and BMES and then increase the measurement to other in the value network.

Use of materials and resources, life Cycle analysis (LCA), type of energy used - black and green energy, energy efficiency, recycling of materials, waste, waste reduction, waste construction, pollution, low carbon emission, GBMI, new collaboration types, sustainable business models, circular business models, UN 17 Goals [1] are all topics and terms that are related to the discussion on GBM. All topics are more or less being related to the term green, green economy, green business, GBM's and green technology. Sustainable business models [2] and circular business model [3] communities have tried to embed the GBM into their terms and vocabularies - however with great difficulties. Especially when sustainable and circular business models turn out not to be green

- but green washing [4] - when deeper investigated both in short and long term perspective - the green parameters and definitions are questioned [5], [6].

All topics shown in Fig. 2 are seen as solutions to fulfil the Global Societies vision, mission and goals to become a green economy. However none have organized the green discussion on the framework of the business model relating and defining the different business model dimensions and business model innovation levels to both the term green and economic terms. Few have tried to bridge the Green Parameters to the Economics Parameters of GBM's. Further few have related GBMI and Green Business Model Development (GBMD). These gaps in literature are the aims of the

\section{2, Relating Measurement Of Green Parameters To Business Model Dimensions And Innovation}

Previous literature study on GBM's and GBMI shows there is not a general accepted, clear and precise definition on a GBM and GBM parameters - neither on GBMI $[5,6,18]$. Although many talks about GBM and GBMI e.g. as related to $100 \%$ Co2 neutral business model, circular business models [7], sustainable business models [7] and even just GBM's [5, 6, 7] the big question is if a business, business models and BMES ever can and will be $100 \%$ green on different GBM parameters and stages (life time of BM 's) and levels of GBMI? As sketched in Fig. 3 our observations are that many BMES, Businesses and BM's will relate to GBMI and try to do GBM reconfiguration - focusing on changing or reconfiguration [9] their operative AS IS BMES, Businesses and BM's into Greener BMES, Businesses and BM’s.

Fewer businesses design [9] Green Businesses (GB) and GBM's that are "born green" and less design new green businesses Startup businesses - that are "born pure green" - and pure green from beginning to end of their business and BM"s life. This would be equal to a startup businesses built with "green gens" in its core business model - the strategic highest level of a business and following all related BM's in the business. Both to AS IS and TO BE businesses we claim this level of GB and GBM is radical andin some cases disruptive - extremely difficult and complex to fulfil, operate and reach. We observe from our case research that most BMES, Businesses and BM's experience "the greening" of a business and its "greening" of related BM's as "a Green Business Model Innovation Journey and Process" - "a Green Business Model Innovation transformation" - from being "black" or "half black" to becoming incrementally more green - but maybe seldom and never completely pure green as sketch in Fig. 4. Our research shows that pure green seems very difficult to become to any BMES, Business and BM - or near to impossible. 
To achieve this stage would include all related BMES, Businesses, BM's at all BMI levels and all GBM parameters to be and become green - and thereby green in their BM's entire value network of BM's related to any BMES.

We propose that businesses $\mathrm{BM}$ can be designed or reconfigured into green on seven different levels - BM component, BM dimensions, BM, BM portfolio, Business, BMES layer and BM/BMES Process level. GBMI can be designed or reconfigured on any of the 7 Green Multi Business Model Innovation (GMBMI) levels and can be measured related to the

- Radicallity of green - defined as degree that the BM's dimensions are changed into green (incremental or radical)

- Complexity of green - defined as how many dimensions of each BM are changed into green

- Reach of green - defined as the impact of the change of green the BM has to the business, vertical- and horizontal BMES [12] or the world

- Time - define as the degree of green of the BM through its entire life cycle

Related to the measurement of a BM's green complexity, if all BM dimensions are changed Green including all BM dimensions components, then the BM could be classified as a Radical GBM. This was however not found in any case in our investigation of 106 SME businesses GBMI projects and processes as seen in table 1.

The businesses in our investigation primarily focused on "greening" or innovate green on the Business Models BM competence dimension and on the component Layer at the technology part of the BM Competence dimension as seen in table 1 and later Table 2. The BM competence dimension consist of 4 component groups [8] - 1. Technology (product- and service technology, production technology and processes technology), 2. HR, 3. Organisational Systems and 4. Culture. The last 3 competence component group were hardly touched upon according to our research. In general it was further a very small component part of the BM competence dimension technology group that businesses changed and wanted to change when doing GBMI as indicated in Fig. 5.

As can be seen it is primarily product technology - energy, water, material - that is changed. This we marked with the grey arrow in the figure. However the businesses also tried to change BM value proposition dimension product component group as they tried to innovate and hereby reduce waste and pollution - Co2. This we marked with the pink arrow in Fig. 5.

We found that there is a clear overweight to focus on innovating, investing and implementing green on the BM competence component technology - mainly reducing use of energy, water, material, consumption and changing energy type to more green energy and/or greener material/resource types. Changing into more green production technologies was also seen in the business cases - e.g. as investment in solar energy systems for renewable energy production to supply the business with more green energy. Further in some businesses cases investment in convex energy production system was seen to reuse heat from building to supply heat to the business. Waste reduction and pollution especially reduction of Co2 emmision was further seen as focus areas for GBMI. There was also focus on recycling waste either internal the business as valuing other business models or by valuing network or customers business models. These last mentioned Green Business Model Parameters (GBMP) [10, 14] have shown to have good impact on reducing pollution $\mathrm{Co} 2$, however the full calculation of resources used to recycle were not seen calculated in the cases of the research. In some cases the impact on Co2 focusing on "greening" material, resources, waste and pollution reduction showed to have much higher impact on $\mathrm{Co} 2$ than reducing energy consumption and changing from black to green energy. However, measurement of Energy consumption as sketch in Fig. 6 was observed in our investigation as easier and less critical to the business to innovate green and implement in the businesses than innovating on other GBM Parameters.

However, very few of the businesses investigated as shown above in Figs. 5 and 6 had really an overview of the Competence BM dimensions energy consumption related to different departments serving or engaging in operation of different BM's. Further the 
energy consumption was not split out to the different BM's and different devices - production technologies - internal the business so it would be possible to see energy consumption pr. BM's and per devices. Hereby it was not possible in most cases to see and analyse the efficiency, Return of Investment (ROI) and progress of the investment in green production technology and relate these to different BM's. Technical there is not much challenge to measure this as advanced software technologies are available and offered by many technology providers. If implemented it could very much help businesses measure Energy consumption in even close to real time $[22,23,24]$. We found examples on energy consumption measured tools and software that could measure on daily, hourly and second basis as seen in Fig. 7.

It was observed that most accountant systems at the businesses were not prepared for splitting out these Green Parameter measurements on different BM's. Measuring the green parameters - black and green energy, water, material and resources consumption, waste and pollution and relating them to different BM's and economic terms is illustrated and sketched in Fig. 8 as an example.

Concerning the supply of black and green energy to a business there is still very much confusion, doubt and actual also a paradox existing. All though energy businesses sell and guaranty supply of green energy to businesses today, reality is that e.g. green electricity and green gas - supplied and sold as Green Energy to a business - often is and can be a mix of "black and green electricity" or "black and green gas". Even businesses gets subsidies for buying green energy although it is in reality a mix of green and black energy as no technology and energy business yet are able to split black and green energy, measure and guaranty pure e.g. green electricity or gas. Only when offered in separate energy systems it can of course be done but these systems are few and expensive to establish and gives other challenges related to the societies and businesses energy system. It is in reality therefore impossible to businesses today to verify and claim that they are pure green on this green parameter and GBM dimension. The national energy system in Denmark and more countries estimate and in some cases verify that pure green electricity and green gas were supplied to the system and region around the specific business - but there is in reality no actual proof of this estimate and claim. It is still an estimate and not based on measurement on actual supply.

Further there is another paradox in this range and that is e.g. that most existing energy systems today can not adapt and store surplus of renewable energy e.g. electricity from windmills on a stormy day [30]. This means that windmills in Denmark in average were "taken out of the wind" - stopped and taken out of production estimated 50 days in 2020. It still resulted in Danish wind energy production businesses pay German and Norwegian businesses money to get rid of overproduction of green energy. But it can also work opposite as e.g. in 2018 German Windmill businesses payed Danish Windmill owners 190 mill DKK to stop the Danish Wind Energy production, because the German Businesses would receive a fine from German State if they stopped their windmill production in Germany. In other words a GBM with a negative earning dependent on which GREEN BMES the businesses are related to.

The green energy BMES is well known as being volatile and the GBM's around green energy is known as being very difficult to manage both for energy businesses and society. Several businesses are therefore working on this GBMI challenge [28] to find better storage system e.g. Power2X systems $[31,32,33]$ able to use surplus of windenergy to power energy heavy production of storable energy. Innovation of new battery systems [xx], new and better energy forecast systems [34,35] are also invested in. Several businesses profit enormous on capitalising on these fluctuations, volatility and different regulations in BMES in the production and supply of green energy. Advanced wireless technology is and can play in future a mayor role in this GBMI and development of Green Energy BMES.

From our investigation we also found that most GBMI investments and projects are today taking place on BM reconfiguration level as seen in Table 1 and 2 - equal to that most GBMI investment are done on existing AS IS BM's. This will be a major focus in future GBM design, because new BM will be pushed to be born green so that "repair" of AS IS BM will be diminished dramatically in the future. EU are already beginning to introduce restrictions on finance businesses possibility to borrow money to businesses investments in e.g. BMI as these have to be proved being green [36, 37]. 
In this process the measurement of the GBM parameters becomes more and more important to secure high quality estimation and verification of the effects and progress of greening of different GBMI projects. However, we found that these measurement tools are still lacking and not implemented in most businesses although they are should be easy to implement.

The majority of the businesses we studied were still limiting their GBMI to greening at a single business model innovation reconfiguration level as seen in Table 2 - but still not in particular designing GBM's. This indicates that businesses are uncertain of GBMI investments and they have not yet fully adapted the GBM approach and GBMI into the entire and higher levels of the business - and the new BMI area. In other words GBMI seems still in the very early days - strategically not yet to have been embedded in to critical and larger parts/levels of the businesses.

As can be seen in both Table 1 and 2 there is much more potential for greening the businesses BM's, when focusing not just on the business BM's competence dimensions - and as we found in our investigation technical part and to some extend value proposition part of GBM. None of the businesses included in our research could therefore be near to classified as $100 \%$ green or pure green to the business.

\section{Measuring incremental, radical and disruptive Green Business Models}

The degree of green of the GBM can however become even " more green" or what we classify as radical and disruptive green. When GBM are related to the degree of "external impact" of greening - the GBM's impact on vertical, horizontal and/or on any BMES can transform GBM's into radical and disruptive GBM's. This can however not be realized without the GBM interacting with other BM's - the Green Multi Business Model approach. If BM relations are established to other BM's outside the BM it will enable green value propositions to flow out of the BM into other BM's and enable receiving and consuming of GBM Value Propositions from other BM's and hereby make the BM greener and enable other BM's to become green. Radicality and complexity however today in many businesses and GBM projects take the view- point from the business side - inside out perspective [11]. However if all BM dimensions are changed green then the BM is totally changed green - meaning it could be classified as being in the disruptive green zone - close to pure green. Dependent on its impact on vertical, horizontal and any BMES - it could be classified as disruptive green. The green impact on the reach axis in Fig. 7 - green to whom - becomes hereby related to defining and measuring how green the BM is and the degree of impact that the green BM and GMBMI in the business has - seen "from outside - in" and "outside - out" viewpoint and hereby the impact of green of GBM's on other BM's. It is measuring the change in existing BM's - "AS IS BM" and also "TO BE BM" - related to the green to the business, green to vertical BMES, green to horizontal BMES and green to any BMES - green to the world.

This transformation and measurement of green will however require very large investments to transform, operate, measure and validate the degree of green. $6 \mathrm{G}$, block chain and beyond technologies might be able to support this measurement but businesses and society have always the final strategic say on How Green they want their GBM to be.

GBMI seems therefore to be a long journey to businesses and society - with certainly a beginning but probably a long end - if ever. There will always be components, dimensions, business models, business model portfolios, businesses, business model ecosystems and business model processes that can be innovated green or more green [10]. Society and Businesses will always learn new technics and approaches to become greener and measure GBM's. GBMI is therefore strongly linked to continuous improvement, continuous innovation and not least learning. Learning will always be the raw material for any Green Multi Business Model Innovation (GMBMI). Learning to become greener and building green competences into technology, HR, organisational systems and culture of the BM's and businesses to be able to innovate BM's to become greener - we expect - will take businesses and society several years - through several iterations, "learning loops" including many "fails and bugs". However theoretical it should be possible to measure GBM and GMBMI on a scale on all BM Dimensions and MBMI levels - not just the BM Competence and Value Proposition dimensions.

\section{Towards Measurement Of Green Business Models}

As more and more businesses face major strategic challenges related to choosing a strategy or road for the business green transformation, it becomes even more interesting to discuss how to measure GBM and GBMI on a scale of "green parameters" 
together with economic parameters of each individual BM's. The green parameters are indicated as discussed above on the BM competence technical area:

1. BM Competence Product Technical area - Material and Resources (as e.g. all types of materials and resources, Energy, Black and Green Energy, Water and even waste from other BM's if used as rawmaterial in the particular BM.

2. BM Value proposition area - Waste, Pollution (including e.g. Co2 and other types of pollution)

However other BM Competence Technical areas as - production and process technology areas - are just in the very beginning of being measured and implemented as measurement objectives in businesses. Typically this measurement are done by LCA measurement tools and calculation systems [27].

In Table 2, we show based on our preliminary investigations in 2020/2021 of 106 Danish Small and Medium size businesses GBMI projects and processes [29] their single green business model strategies. All businesses were screened by a screening questionnaire and all data from this screening were carefully analysed, grouped and scaled into different green categories and strategies as seen in Table 1 and 2. Our investigation showed that most GBMI strategies in these SME's were focused on limited numbers of Business Model dimensions table 1 and mostly Green Business Model reconfiguration Table 1 and 2. In GBMI research, we distinguish between Green Business Model Innovation (Green Business Model Design and Green Business Model Reconfiguration) $[10,25]$ and Green Business Model Development. Green Business model development focus on implementation and introduction, growth, maturity and decline phase of the GBM with classical BM development tactical parameters, tools and actions. Green Business Model Development covers also the continuous improvement of GBM's. We found very few GBM cases that had entered the GBM development phase [8 incidence], often because the businesses could not find enough efficiency in investing green and did not have the numbers available on green parameters and economy measured on individual BM's - both on AS IS BM's and To BE BM's. Those we found that had invested in GBM's were primarily into the introduction phase and mostly focusing on initial promotion and improvement of GBMs and focusing on branding their business or BM on being green. However they did not have the detailed numbers separated on the individual claimed GBM's. In Fig. 6 we show an example on GBM's from one anonymous business called Swedspan, that had the numbers available on elected Green parameters and some BM's but only at an overall business level for economy.

In Fig. 9 we divided the green parameters technology (material and ressources) - coming in to the business (Outside in) and those value propositions green parameters offered by the different business models - going out from the business (inside out) to different BMES. As Swedspan is using more energy types (e.g. Electricity, Gas, Diesel) the energy input to the business is calculated in $\mathrm{KWH}$ and netto ton as seen in Fig. 9. Hereby we relate the Green parameters to the business model relation axiom quadrant 2 and 3 [11]. As Swedspan has no Green Parameter measurement on e.g. LCA, device energy consumption, LCA on production and process technology and other GBM Dimensions and GBMI levels inside the business - yellow lower triangle in Fig. 9 - it is not possible to comment on green parameter measurement inside the BM's related to quadrant 1 in the relations axiom.

We also found very few GBM in the GBM Design phase [12 incidence] indicating that most GBMl are not focused on creating BM 's as GBM when they are "born". None of the GBMI projects and GBM could be related to radical or disruptive GBMI.

There is still not much validated research that document the efficiency of these GBMI projects and developments. However, some of the GBMI and Development projects were carried out although due to subsidies [13] and arguments of energy cost savings but indications show that material and resource savings could be able to give even higher cost savings and even more value adds to the businesses. In this case Life Cycle analysis (LCA) [26, 27] of BM's becomes important and a new measurement area for GBM's. LCA studies of a BM is a "snapshot in time" measure of burdens. The lower the burdens across the LCA of a BM or a network of BM's, the smaller the footprint - $\mathrm{CO} 2$ impact. An LCA measures burdens-what goes in (how much energy and raw materials it takes to make a BM or a network of BM), and what goes out (how much waste, water pollution and emissions to air) across the BM's life cycle.

As earlier mentioned our investigation showed that the businesses primarily focus on "greening" the BM competence dimension level and at Business Model reconfiguration - changing AS IS BM's. In Table 2 we show that the GBMI is mostly taken place at 
the component level. (104-incidence Table 2).

This indicates that GBMI in the businesses investigated is taking place at a very small, bottom and limited level and area in the businesses. We found that majority of businesses are limiting their GBMI to greening a single business model (46 incidences) and mostly reconfiguration of these single business models - not in particular designing GBM's. This also indicates that businesses have not yet fully adapted the GBM approach and GBMI into the entire and higher levels of the business - and this new BMI area. It indicates that more BMI levels are not included in the GBMI as a core of BMI in the businesses. In other words, GBMI seems still in the very early days - strategically not yet embedded in to critical and larger parts/levels of the businesses. In other words we found no businesses into radical and disruptive GBMI.

\section{Discussion}

Green Strategic Business Model Innovation is a very new strategic BMI game and tool that can potentially be used in many businesses globally in the future. Our study showed how SME businesses strategically handle single GBMI in early 2020 - early 2021. The research showed clearly that GBMI by SME's are in the very beginning of "the roll out phase" - an maybe in more cases not even with a very strategic focus - but more as a necessity or tricked by a "push" by society, politically $[15,16,17]$ and from different BMES's $[18,19,20,21]$. The SME business clearly focus on competence BM dimension innovation and to some extend value proposition dimension at a BM component level - mostly changing product and production technology into greener technology. We expect that this will expand into other BM dimensions and BMI levels as soon as businesses have penetrated the potential of the BM competence technology area. Then GBMI will move into more "soft" and qualitative BMI areas and levels e.g. Human Ressource, organisational systems, culture and the business level. This will mean that businesses will begin to "be green" - radical and maybe disruptive green. This will mean that businesses will demand related business models, network and even users and customers to innovate and act green. Therefore, our expectation is that GBMI and GBMD will spread out to the entire business value network and BMES's. We are still in the process of finding measurements tools for other BM Dimension areas. Measuring these upcoming areas we expect will be more difficult and challenging to measure and will require other measurement competences than pure technical and quantitative engineering skills.

It can be criticized that the data used in the paper is taken up on behalf of two Green Business projects [14, 29] that have focus on SME's and specific GBM Parameters [10] - e.g. energy consumption, the relation between black and green energy, material and resources and to some extend pollution - Co". This could biased the findings on businesses focus on GBMI dimensions and levels Table 1 and 2. However it is our observations from other green business projects that GBMI is in the very initial stage - both at small and large businesses.

\section{Conclusion}

The article reports on an investigation of How to measure Green Business Models and Green Business Model Innovation? The research was carried out in 2 Green Business Model Innovation projects - The danish ECSMV project - www.ecsmv.dk. and the Nordic EU Interreg Kask Greenbizz project - www.Greenbizz.eu.

In the ECSMV Green Business Model (GBM) project we were able to investigate 106 SME businesses green business model innovation (GBMI) projects. The purpose was to find out How green the businesses were and to find out How to measure GBM and GBMI. The investigation showed clearly that most businesses strategical approach related to GBM is a single GBMI approach at a very low, narrow and bottom level of the GBMI potential. Most business investigated focused on BM competence dimension especially green technology - producttechnology and production technology related. Business Model dimension and the business model component level. Green Business Model Innovation in the SME businesses was found mainly taking place at a very small and limited GBMI level in the businesses. Businesses seemed not yet to have adapted the GBM approach and GBMI into their higher levels of their businesses. Very few businesses had spread out their GBMI to their value network.

In the Greenbizz project we were able to investigate and innovate different GBM and GBMI measurement tools with the aim in near future to innovate a GBM and GBMI dashboard that can measure How Green a BM, Business and BMES really are - and in 
realtime. The research showed that several measurement tools exists already on energy consumption but it is not measured out in general on all devices in the businesses according to our investigation - most often if so only on temporally basis. This means that businesses lack knowledge on which BM's and devices consume energy and further what kind of energy - green and black. All though the energy providers sell and to some extend guaranty green energy supply the energy supply is still a mix of black and green energy as no business yet can trac and trace energy types.

\section{Further Research}

The researchers intend to investigate further Green Multi Business Model and Single Green Business Model Innovation in Nordic Countries through the EU KASK GreenBizz project - www.GREENBIZZ.COM. More than 60 business cases in Norway, Sweden and Denmark will be investigated intensively. Further about 680 businesses in Central Region Denmark will be investigated in 2021 and 2022.

\section{Declarations}

All manuscripts must contain the following sections under the heading 'Declarations'.

If any of the sections are not relevant to your manuscript, please include the heading and write 'Not applicable' for that section.

\section{All sections are relevant to the manuscript.}

To be used for all articles, including articles with biological applications

Funding (information that explains whether and by whom the research was supported)

The research was supported by the ECSMV project and the Greenbizz project.

Conflicts of interest/Competing interests (include appropriate disclosures)

There is no conflicts of interest.

Availability of data and material (data transparency)

Detailed background Data is confidential

Code availability (software application or custom code)

Not relevant for this paper.

Authors' contributions (optional: please review the submission guidelines from the journal whether statements are mandatory) Not relevant for this paper

Additional declarations for articles in life science journals that report the results of studies involving humans and/or animals

Not relevant for this paper

\section{References}

1. UN 17 goals - https://sdgs.un.org/goals

2. Bocken, N.M.P et all (2014) A literature and practice review to develop sustainable business model archetypes - Journal of Cleaner Production Volume 65, 15 February 2014, Pages 42-56

3. Bocken, Nancy; Schuit, Cheyenne; Kraaijenhagen, Christiaan (2018) Experimenting with a circular business model: Lessons from eight cases Environmental Innovation and Societal Transitions DOI: 10.1016/j.eist.2018.02.001 2018

4. Delmas, M. A., Burbano, V. C. (2011). The drivers of greenwashing. California Management Review, 54, 64-87. 
5. Sommer, A (2012) Managing Green Business Model Transformations Springer Verlag ISBN 978-3-642-28848-7

6. Lindgren P., Susanne Durst, Xingyu Zhu, Gitte Kingo, Rita (2021) Green Business Models literature study - What did we learn? Journal of Nordic Baltic ICT River publishers In press

7. Marina P.P. Pieroni*, Tim C. McAloone, Daniela C.A. Pigosso (2017) Comparison of scopes of CE-oriented and sustainabilityoriented business model innovation approaches. Technical University of Denmark (DTU), Department of Mechanical Engineering, Nils Koppels Alle 404 / Room 229, DK- 2800 Kgs, Lyngby, Denmark

8. Lindgren P., (2018) The Multi Business Model Innovation Approach - Part 1 River Publishers

9. Lorenzo, M., Christopher L. Tucci, Allan Afuah (2017) a critical assessment of business model research Academy of Management Annals 2017, Vol. 11, No. 1, 73-104. https://doi.org/10.5465/annals.2014.0072

10. Lindgren P. (2021) A Scoping Review and Framework of Green Business Models Related to Future Wireless Technology: Bridging Green Business Models to Future Wireless Technology Journal of NBICT, Vol. 1, 1-34. doi: 10.13052/nbjict1902$097 X .2020 .016$

11. Lindgren, P., and Rasmussen, O. H. (2018) The business model relation axiom. In: River Publishers Series in Multi Business Model Innovation, Technologies and Sustainable Business (eds), The Multi Business Model Innovation Approach Part 1, pp 119-147.

12. Lindgren, P. (2016) The business model ecosystem. Journal of Multi Business Model Innovation and Technology, 4, no. 2, 61-110.

13. smv:digital https://smvdigital.dk/groen-tilskudspulje/tilskud-til-privat-raadgivning-paa-100-000-kr

14. The Greenbizz project - EU Interreg. Kask - https://www.greenbizz.eu/

15. EU Green Deal Cal/https://ec.europa.eu/commission/presscorner/detail/en/ip_20_1669

16. EU COE Transmission - https://ec.europa.eu/info/business-economy-euro/banking-and-finance/sustainable-finance/eutaxonomy-sustainable-activities_en

17. EU taxonomy for sustainable activities https://ec.europa.eu/info/business-economy-euro/banking-and-finance/sustainablefinance/eu-taxonomy-sustainable-activities_en\#whathttps://www.globaltimes.cn/content/1209841.shtml

18. Edie https://www.edie.net/news/9/China-s-carbon-neutral-target-for-2060-What-does-it-mean-for-global-climate-action-/

19. Ministry of Finance Green Climate Deal Danish Government and Industry (2020)

https://fm.dk/nyheder/nyhedsarkiv/2020/juni/bred-klimaaftale-bringer-danmark-tilbage-i-den-groenne-foerertroeje/

20. Greenest City Vancover 2020 - https://vancouver.ca/files/cov/Greenest- city-action-plan.pdf

21. EU Horizon 2020 Green Deal actions and applications 26 of January 2021 Linkedln 2021

22. Nordlys/Niras - https://norlys.dk/? gclid=CjwKCAjwvMqDBhB8EiwA2iSmPPB8_y15CYEZ1/szzNJahNaKi_OIKxmLdt2wpiMYnK3LMtDmXupbKBoCwRIQAvD_BwE

23. Tracknamic - https://www.tracknamic.com/functionalities/\#fuel-consumption-based-on-probe

24. Kamstrup Metro - https://www.kamstrup.com/en-en

25. Lindgren, P. (2021) The Green Multi Business Model Innovation Brain Journal of Mobile Multi Media River Publishers

26. Finnveden, Göran, Michael Z. Hauschild, Tomas Ekvall, Jeroen Guine', Reinout Heijungs, Stefanie Hellweg, Annette Koehler, David Pennington, Sangwon Suh (2009) Recent developments in Life Cycle Assessment Journal of Environmental Management 91 (2009) 1-21

27. Guinée, Jeroen B., Reinout Heijungs, Gjalt Huppes, Alessandra Zamagni, Paolo Masoni, Roberto Buonamici, Tomas Ekvall, and Tomas Rydberg Life Cycle Assessment: Past, Present, and Future Environ. Sci. Technol. 2011, 45, 1, 90-96 Publication Date:September 2, $2010 \mathrm{https://doi.org/10.1021/es101316v}$

28. Energinet Danmark 2021 -

29. ESMV - projektet - https://ecsmv.dk/

30. https://www.wind-watch.org/news/2019/12/12/tyskere-betaler-for-at-fa-slukket-danske-vindmoller-nar-det-blaeser/

31. https://en.wikipedia.org/wiki/Power-to-X

32. https://

Page $10 / 17$ 


\section{3. https://}

34. https://ens.dk/en/our-services/projections-and-models

35. https://www.ecmwf.int/en/forecasts

36. EU CoE Transmission - https://ec.europa.eu/info/business-economy-euro/banking-and-finance/sustainable-finance/eutaxonomy-sustainable-activities_en

37. EU taxonomy for sustainable activities https://ec.europa.eu/info/business-economy-euro/banking-and-finance/sustainablefinance/eu-taxonomy-sustainable-activities_en\#what

38. Biographies

\section{Tables}

Table 1. Green Business Model Innovation related to Green Business Model components and Dimensions in 106 SME Businesses 2020/2021 [29]

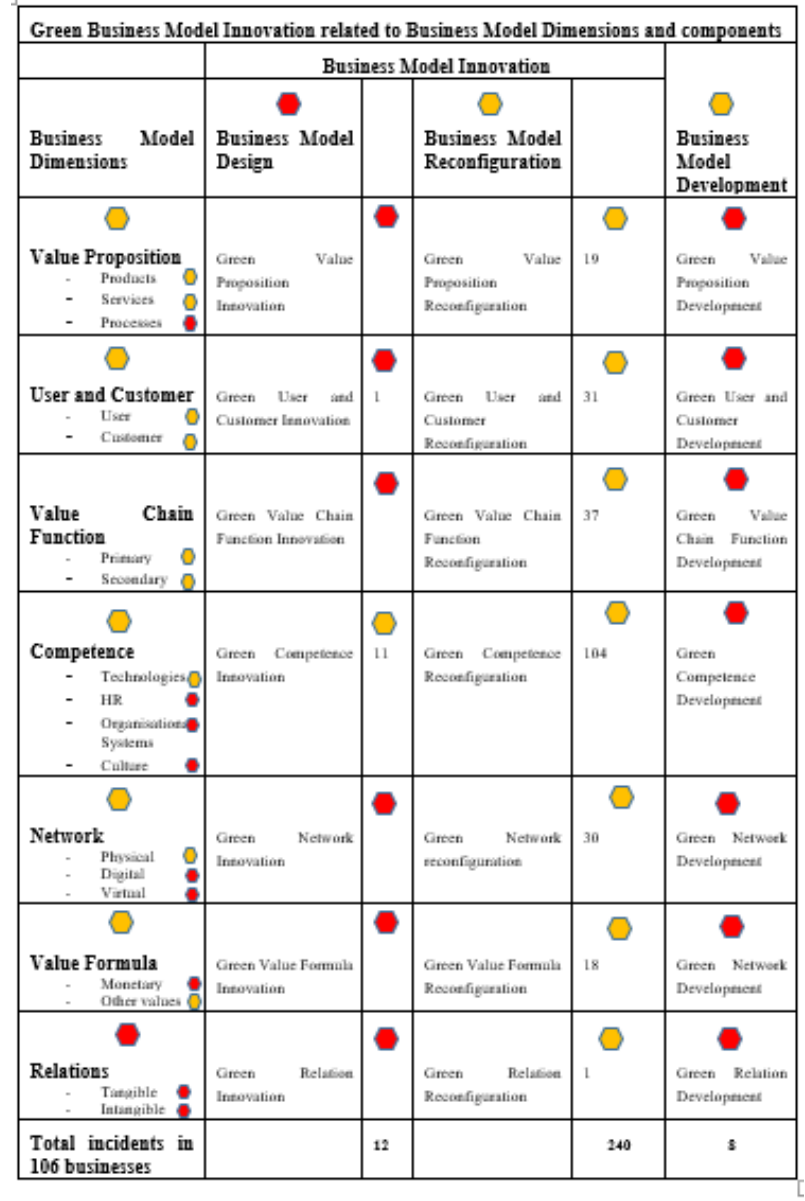

= No GBMI activity and inrestment

$\mathrm{O}=$ Some GBMI activity and investment

Table 2. Single Green Business Model Innovation related to Business Model Innovation Levels [29] 


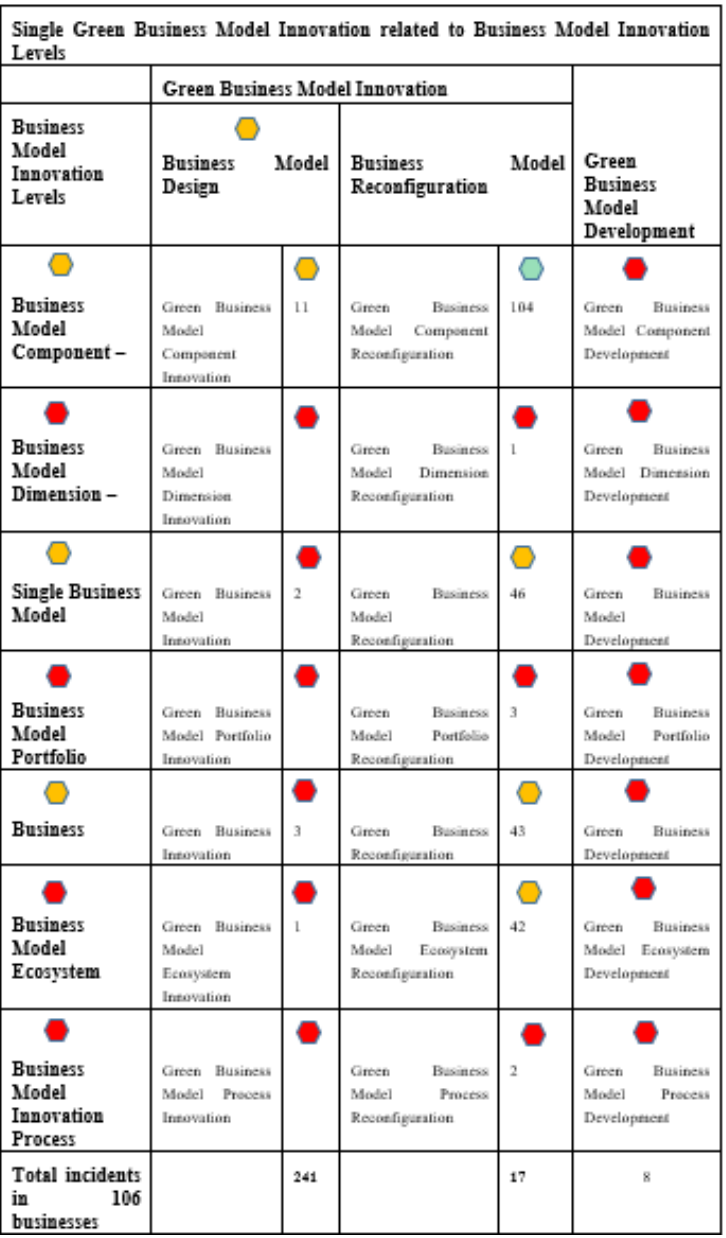

\section{Figures}




\section{From leaky to loopy}

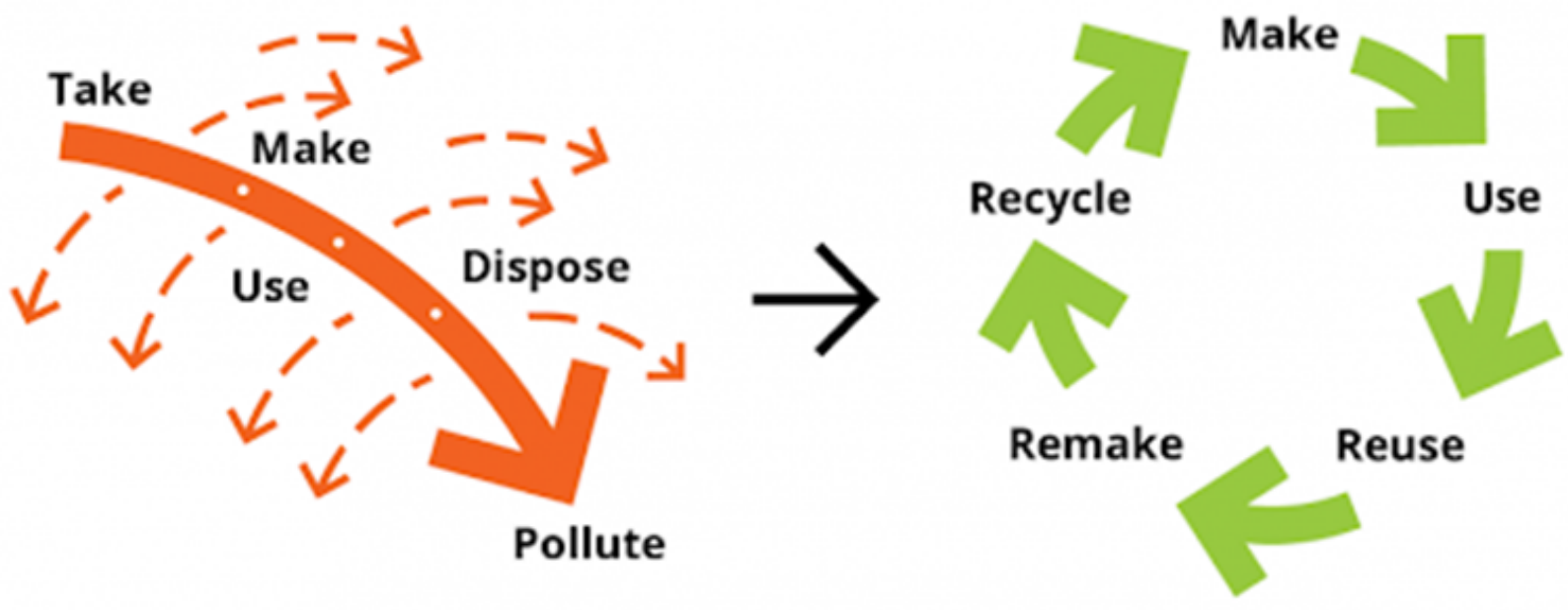

Figure 1

Green Business Model Process

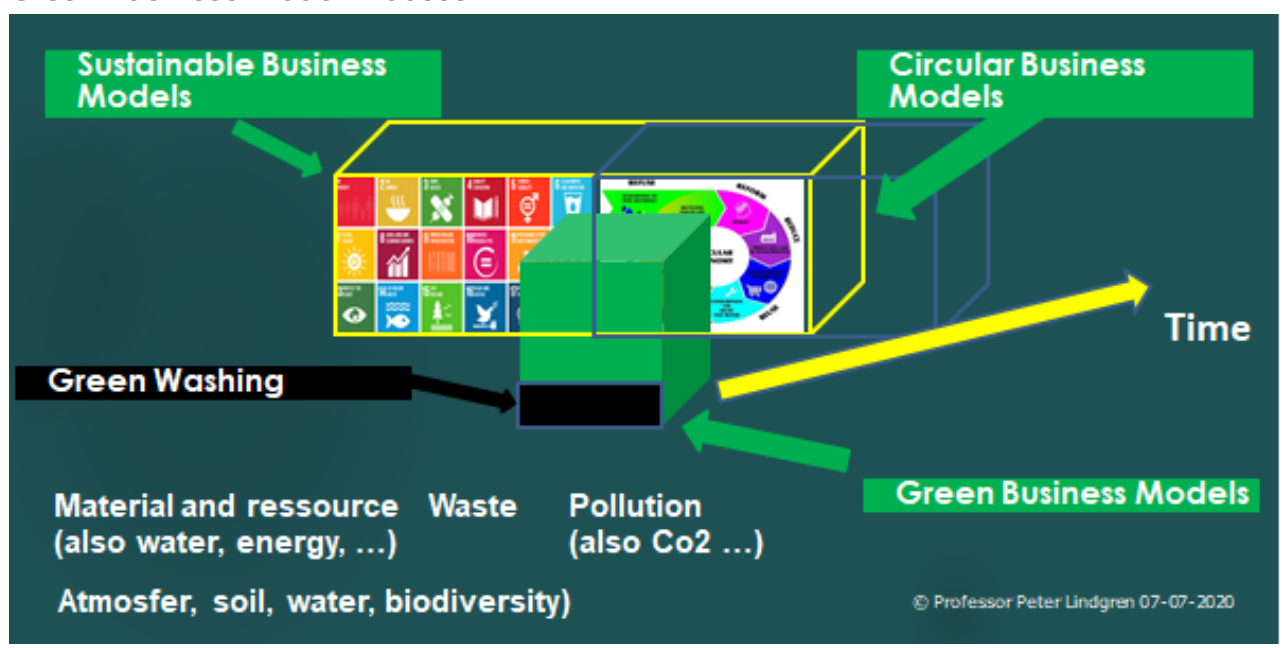

Figure 2

Green Parameters and topics used in Green Business Model discussion. 

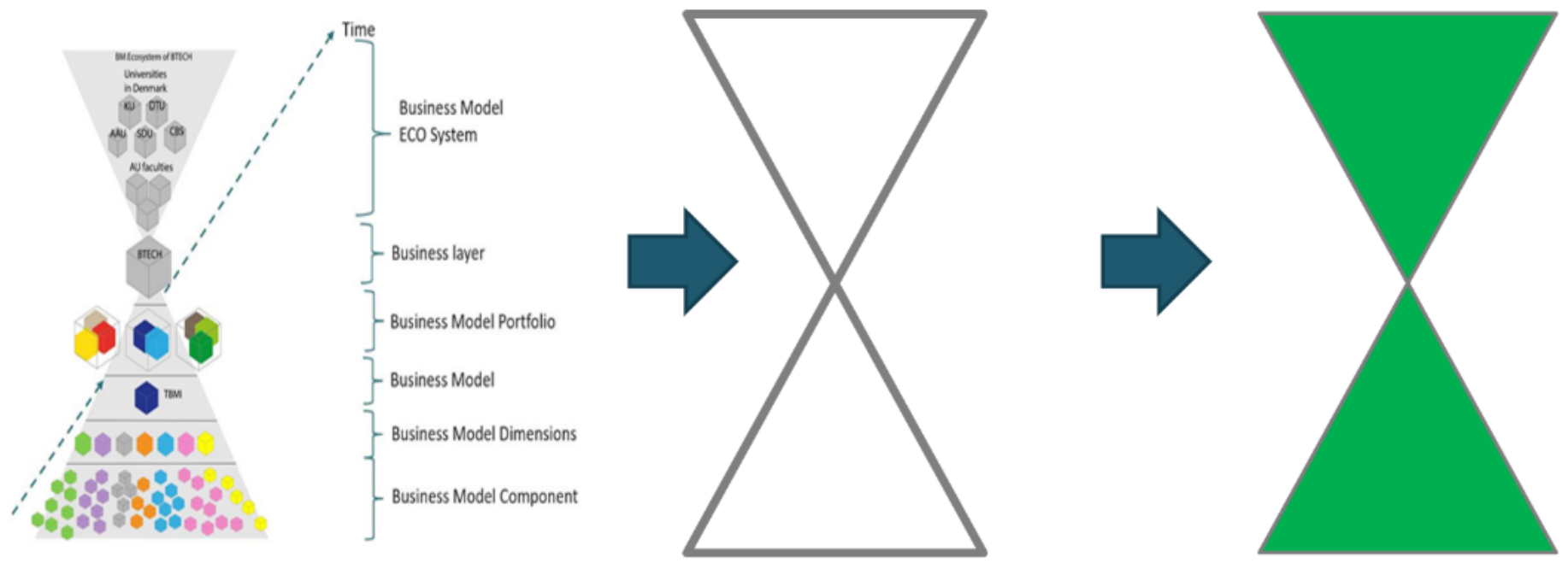

\section{Figure 3}

Different Stages and levels of Green Business Model Innovation inspired by Lindgren 2021 [8]

\section{Radicality}

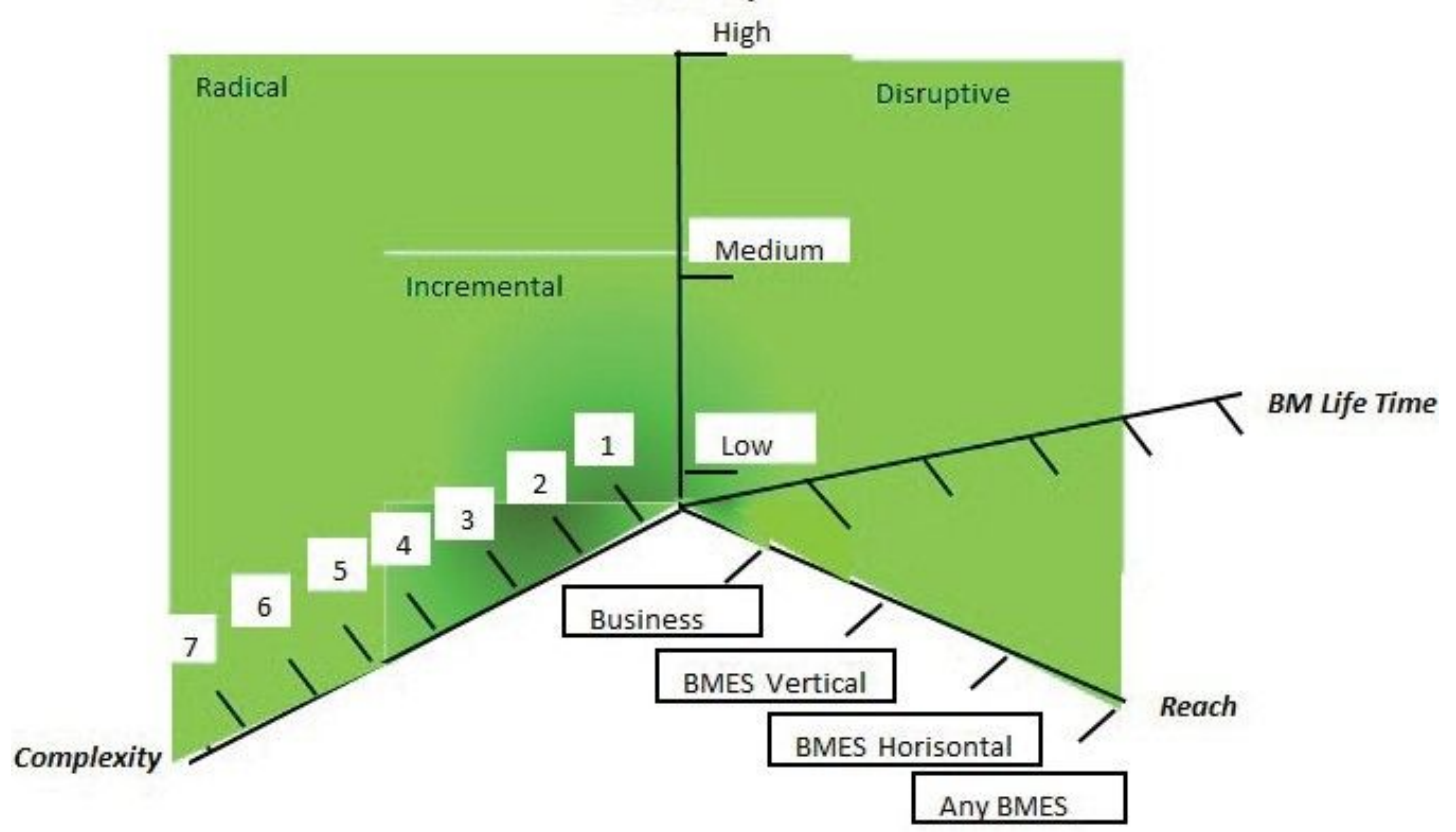

\section{Figure 4}

A four dimensional GMBMI framework adapted from Lindgren [10]. 


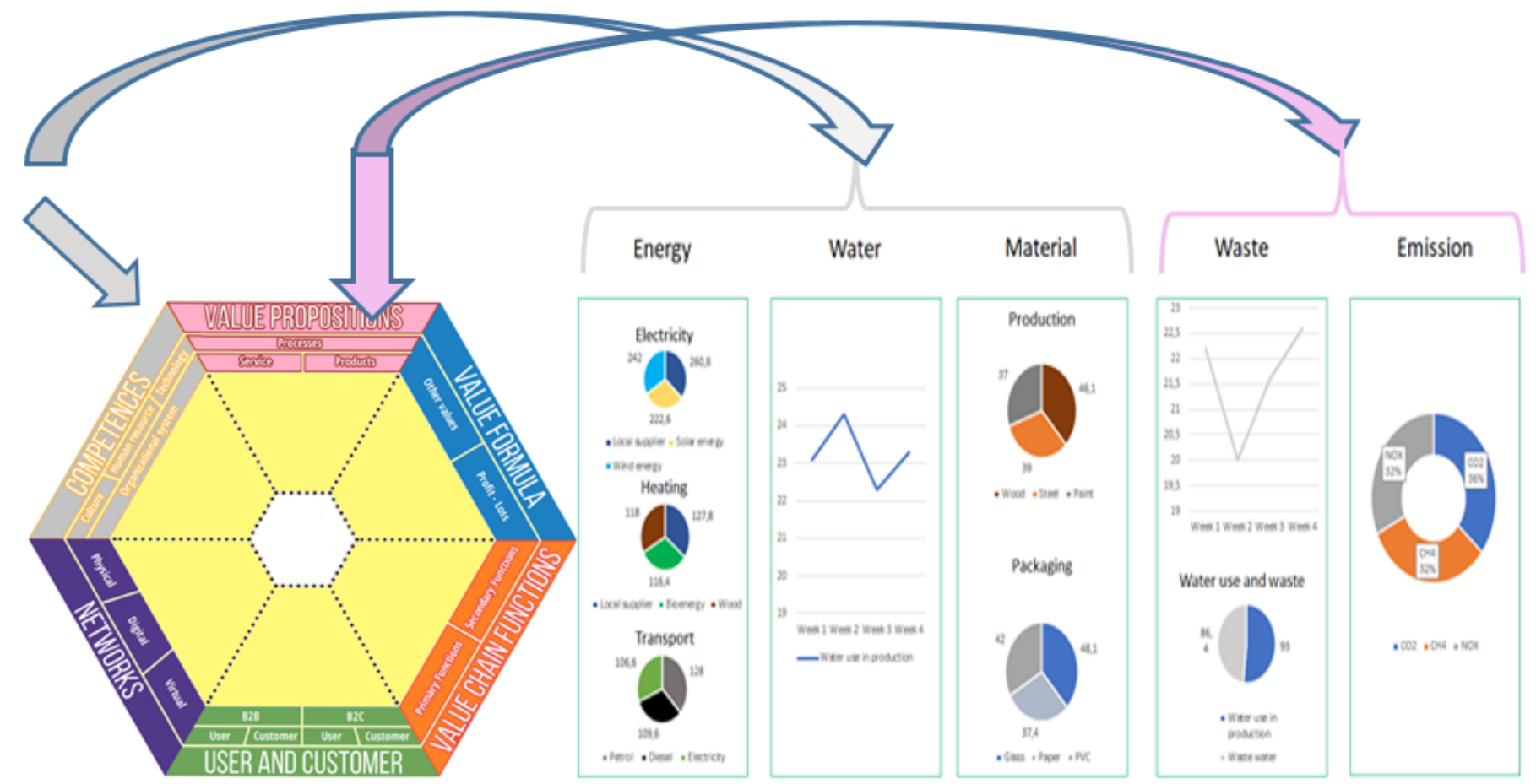

\section{Figure 5}

Example of a Green Business Modelling Dashboard with focus related to Competence BM Dimensions and technical components.

\section{Energy}

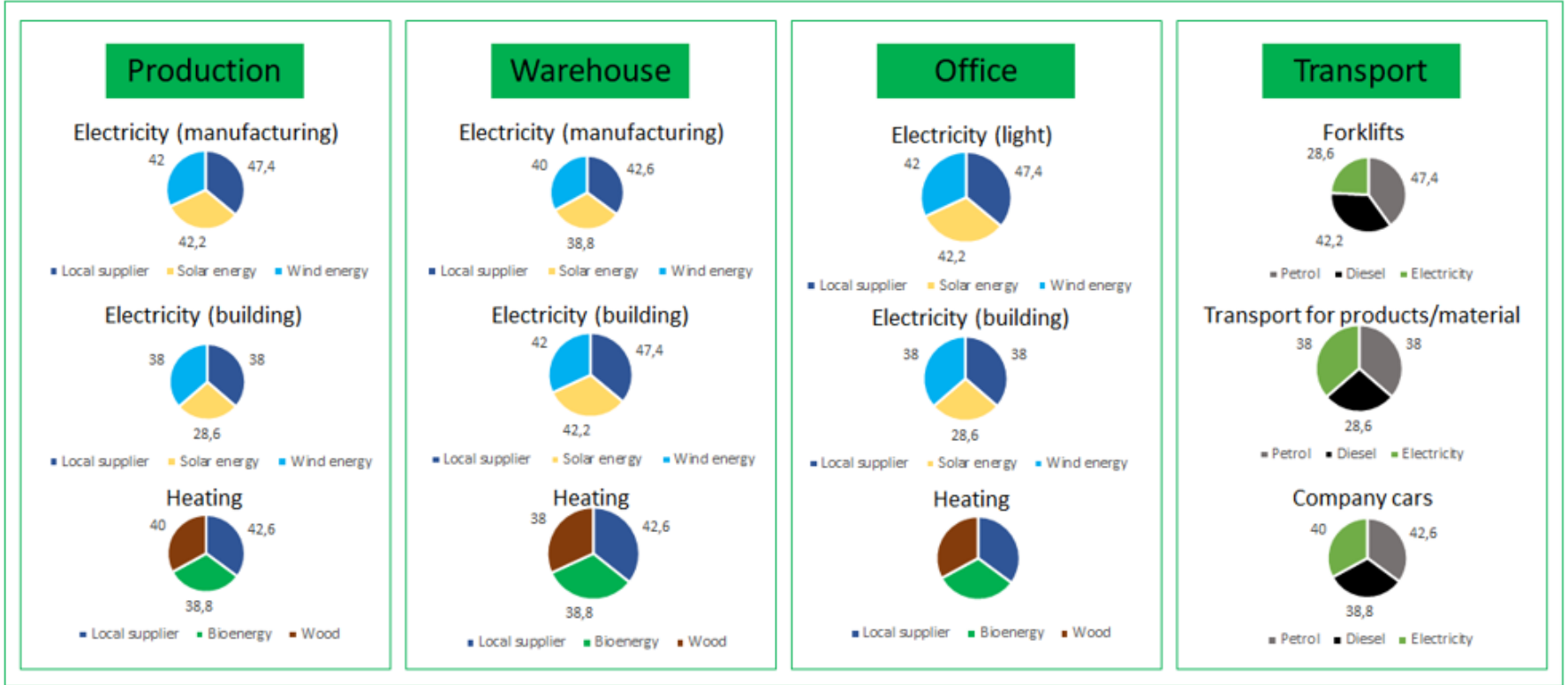

Figure 6 
Example of a Green Business Modelling dashboard focused on Energy consumption - black and green energy Competence BM Dimension and technology component group measured on different business model areas.

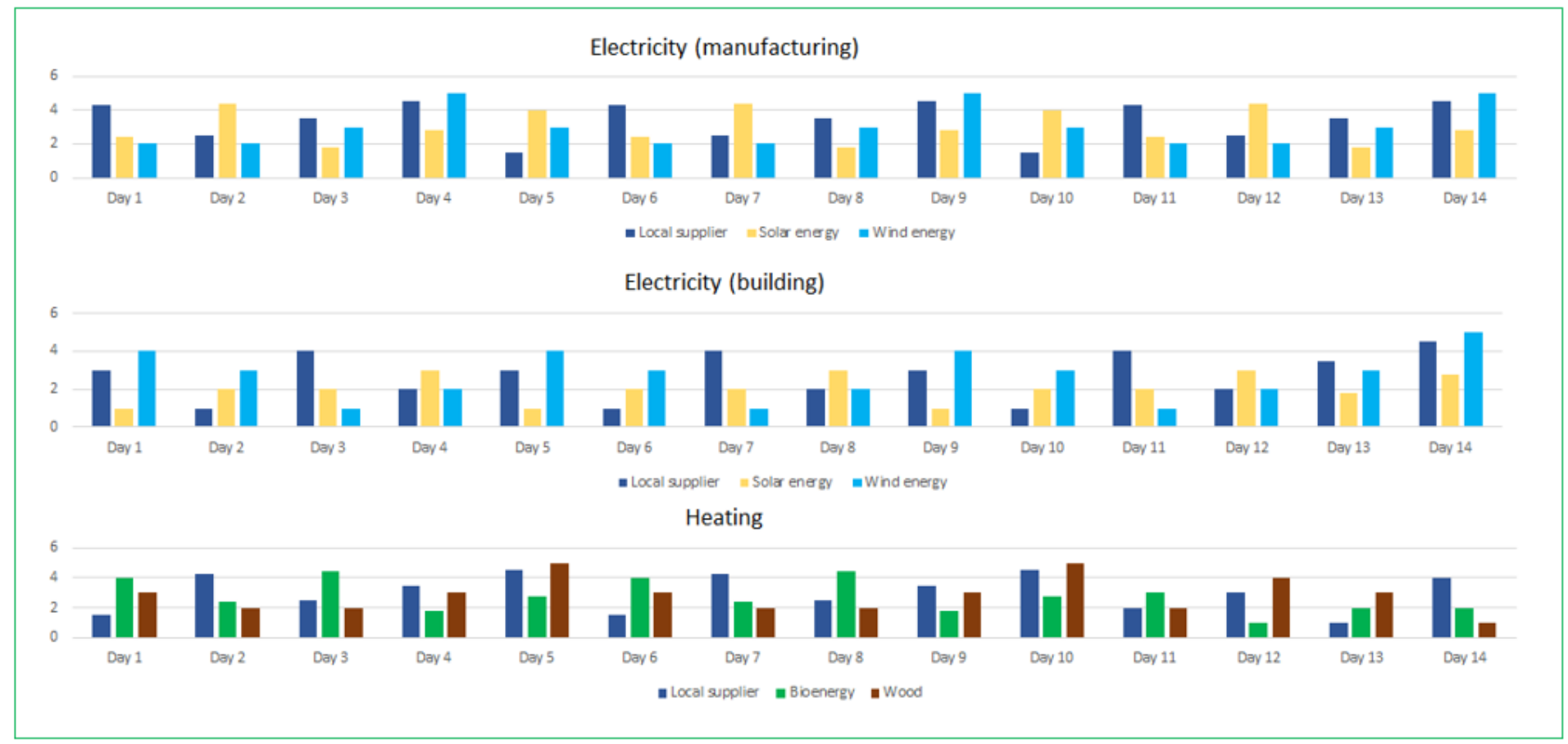

Figure 7

Example of a Green Business Modelling dashboard focused on Energy consumption and energy source types on daily basis separated on supplier, black and green energy in different business model areas.

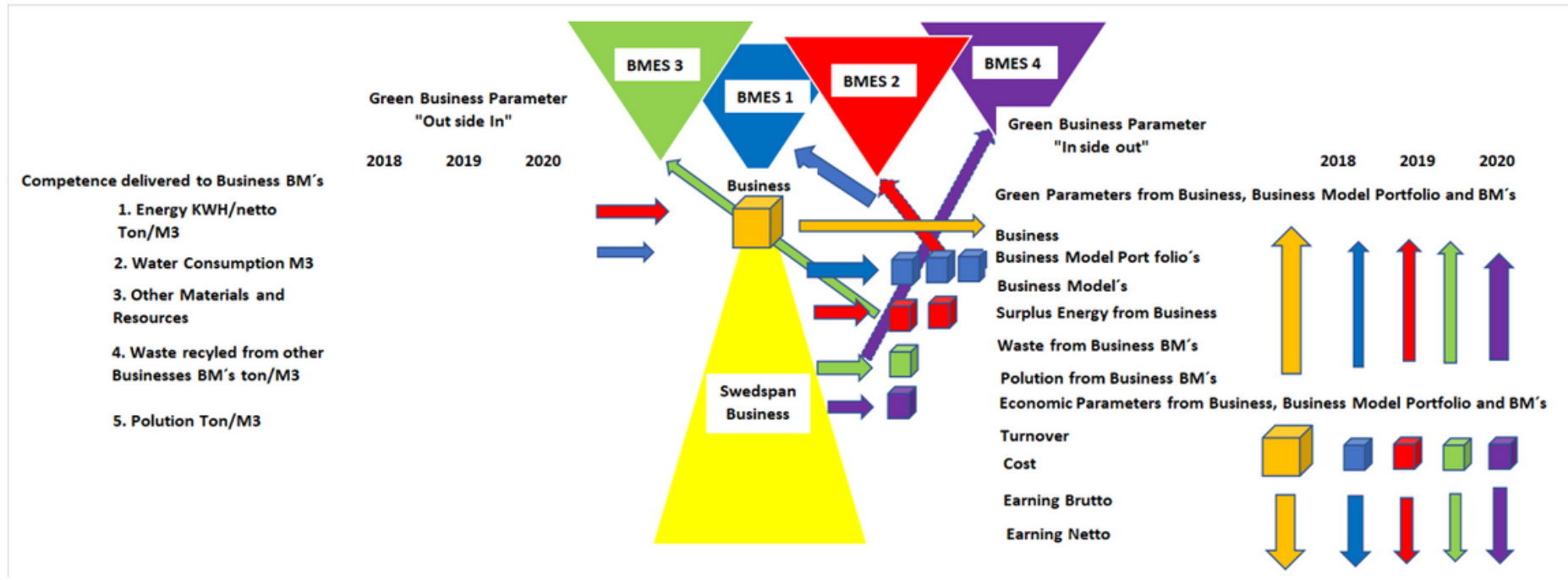

Figure 8

Model for measuring green parameters and economic parameters for business, business portfolio, Business Models 


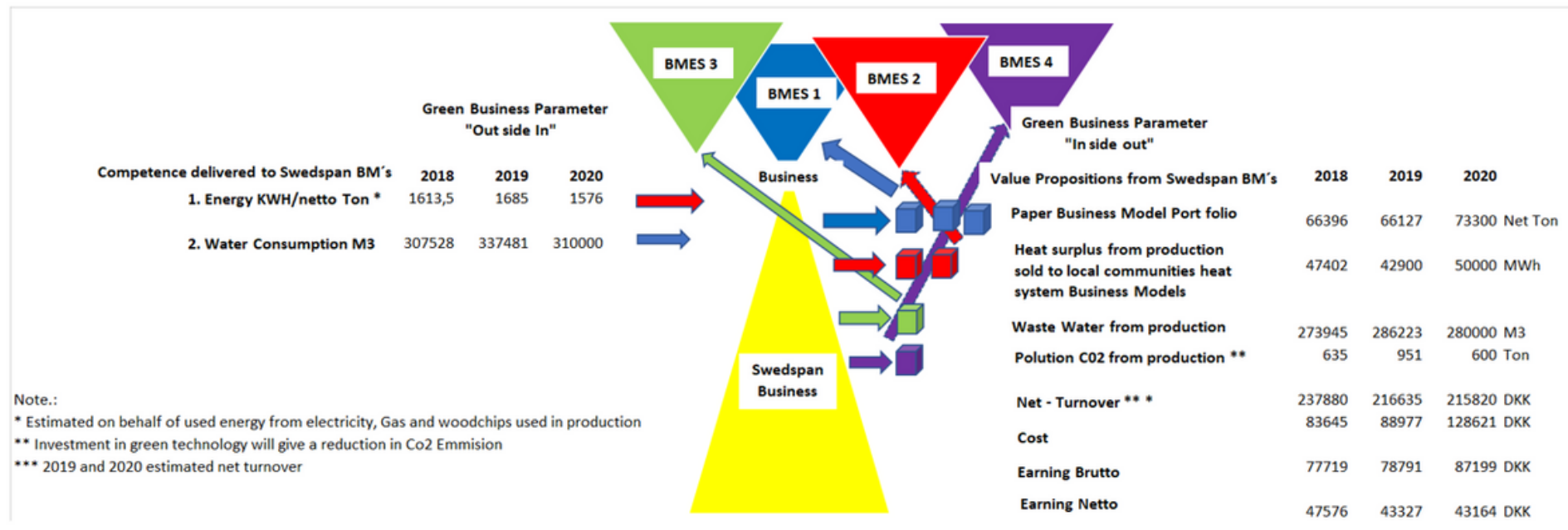

Figure 9

Green parameters "outside in" and "inside out" together with Swedspan's total turnover, cost and earning measured at business level 